\title{
CHRONOLOGIA I PERIODYZACJA CMENTARZYSKA Z EPOKI BRAZZU I WCZESNEJ EPOKI ŻELAZA W DOMASŁAWIU, POW. WROCŁAWSKI, NA PODSTAWIE DATOWANIA RADIOWĘGLOWEGO
}

\author{
THE CHRONOLOGY AND PERIODIZATION OF THE BRONZE \\ AND THE EARLY IRON AGE BURIAL GROUND IN DOMASŁAW, \\ WROCŁAW DISTRICT, BASED ON RADIOCARBON DATING
}

The article presents the results of the radiocarbon dating and Bayesian analysis of ${ }^{14} \mathrm{C}$ dates of bones from the burial ground in Domasław. The Bayesian analysis used the relative chronology obtained based on the characteristic features of grave goods and the assigning of individual burials to specific periods of the late Bronze Age (III EB - V EB) or the early Iron Age (HC - LtA). A coherent chronological model of the burial ground was accepted after assuming that graves with transitional features, attributable to two subsequent periods, could have been contemporary of graves from one or the other period. The temporal frames of particular periods calculated by the model allow us to improve previously published chronological diagrams of the late Bronze Age and the early Iron Age in the region.

KEY WORDS: radiocarbon dating, Bayesian analysis, Bronze Age, Domasław

\section{METODYKA I WYNIKI DATOWANIA ${ }^{14} \mathrm{C}$ KOŚCI Z DOMASŁAWIA}

Ze stanowiska w Domasławiu do datowania ${ }^{14} \mathrm{C}$ wyselekcjonowano próbki kości z 50 grobów ciałopalnych (program realizowany w ramach projektu Narodowego Centrum Nauki „Przemiany w obrządku grzebalnym w epoce brązu i wczesnej epoce żelaza jako wyraz zmian społeczno-kulturowych w południowo-zachodniej Polsce" - projekt nr UMO-2014/15/B/HS3/02463 podpisany 10.08.2015). Kości były datowane z użyciem techniki AMS (akceleratorowej spektrometrii mas), w Poznańskim
Laboratorium Radiowęglowym (Goslar et al. 2004, 5-11). Na skutek kremacji ciał, w żadnej z próbek kości (prócz jednej, najmłodszej) nie zachował się kolagen, będący frakcją najczęściej wykorzystywaną w datowaniu ${ }^{14} \mathrm{C}$ tego materiału.

Ekstrakcję kolagenu z najmłodszej próbki (z grobu 10336) przeprowadzono standardową metodą Longina (1971, 241-242), z dodatkowym zastosowaniem $\mathrm{NaOH}$ dla usunięcia kwasów humusowych, oraz ultrafiltracji (Bronk Ramsey et al. 2004, 155-163; Brock et al. 2010, 106-107) dla usunięcia krótszych łańcuchów aminokwasowych powstałych w wyniku degradacji kolagenu w kościach zalegających w osadzie. Zadowalająca jakość otrzy- 
manego kolagenu (wydajność ekstrakcji 0,7\%) została potwierdzona wynikiem pomiaru stosunku C/N $(3,33)$, który mieści się w ogólnie przyjętym przedziale dopuszczalności (van Klinken 1999, 689-691).

W przypadku pozostałych kości, ich niemal biały kolor wskazywał przepalenie w wysokiej temperaturze, przekraczającej $600^{\circ} \mathrm{C}$ (tzw. kalcynację). Badania Lantinga et al. (2001, 249-254) pokazały, że w procesie kalcynacji zachodzi rekrystalizacja apatytu, którego ziarna stają się większe i lepiej upakowane niż w apatycie kości żyjącego osobnika. Dzięki temu apatyt staje się bardziej odporny na wymianę węgla $\mathrm{z}$ otoczeniem, i również dzięki temu, daje się go odizolować od mniej odpornego wtórnego kalcytu, ewentualnie wykrystalizowanego w kości po jej odłożeniu w osadzie. $Z$ tego względu preparatyka takich materiałów do datowania ${ }^{14} \mathrm{C}$ obejmuje usunięcie resztek frakcji organicznej (przez traktowanie $\mathrm{w} \mathrm{NaClO}_{2}$ ) oraz usunięcie ewentualnego wtórnego kalcytu (przez traktowanie w $\mathrm{CH}_{3} \mathrm{COOH}$ ) i dopiero po tych etapach prowadzi się rozkład apatytu, uwalniając $\mathrm{z}$ niego węgiel przeznaczony do pomiaru ${ }^{14} \mathrm{C}$.

Jak wykazały późniejsze badania (Zazzo et al. 2009, 601-611; Zazzo et al. 2013, 1409-1421), w czasie kalcynacji może zachodzić wymiana węgla z otoczeniem, m.in. z $\mathrm{CO}_{2}$ zawartym w powietrzu oraz $\mathrm{z} \mathrm{CO}_{2}$ powstałym przy spalaniu paliwa służą- cego do kremacji. Takie procesy mogłyby wpływać na wynik datowania radiowęglowego, gdyby kalcynacji poddano stare kości (gdyby kremację przeprowadzono długo po śmierci osobników) lub gdyby paliwem było drewno bardzo stare już w momencie kremacji (względnie węgiel kamienny). W przypadku kości z grobów w Domasławiu, trudno zakładać występowanie takich problemów.

Wyniki datowania ${ }^{14} \mathrm{C}$ przedstawia Tabela 1. Próbki w Tabeli 1 uszeregowano na podstawie datowania względnego (Gediga 1982, 49-59; Gediga 2019, w tym tomie), wykonanego w oparciu o charakterystyczne cechy wyposażenia grobów. Symbole poszczególnych okresów podane w tabeli odpowiadają podziałowi późnej epoki brązu i okresu halsztackiego zaproponowanemu dawno temu przez J. Kostrzewskiego (1948, 118-359) i przywoływanemu w licznych późniejszych publikacjach (np. Kostrzewski et al. 1965, 119-228; Dąbrowski 2009, 17, tab. 1; Gediga 2013, 383, tab. 1). W datowaniu względnym grobów z Domasławia (Gediga 2019, w tym tomie), określającym ich przypisanie okresom systemu J. Kostrzewskiego (III, IV i V w późnej Epoce Brązu, HC i HD w Hallstacie), wyszczególniono groby o cechach przejściowych, dające się przypisać obydwu następującym po sobie okresom, tj. II/III EB, III/IV EB, IV/V EB, V EB/ $\mathrm{HC}$ oraz HC/HD.

Tabela 1. Wyniki datowania ${ }^{14} \mathrm{C}$ próbek kości ze stanowiska w Domasławiu. Podane są $68 \%$ i 95\% przedziały ufności dat kalibrowanych pojedynczych próbek oraz przedziały ufności dat obliczonych modelowo (Model B) przy wykorzystaniu informacji pochodzącej z datowania względnego. * - (Gediga 1982; 2019).

Table 1. Results of $14 \mathrm{C}$ dating of bone samples from the site in Domasław. The $68 \%$ and $95 \%$ confidence intervals of dates of calibrated individual samples are given, as well as the confidence intervals of dates calculated with models (Model B) using information from relative dating. * - (Gediga 1982, 2019).

\begin{tabular}{|c|c|c|c|c|c|c|c|}
\hline Nr grobu & Nr lab. & $\begin{array}{c}\text { Wiek } \\
{ }^{14} \mathrm{C} \text { BP }\end{array}$ & $\begin{array}{c}\text { Data } \\
\text { kalibrowana } \\
\text { BC }(68,2 \%)\end{array}$ & $\begin{array}{c}\text { Data } \\
\text { kalibrowana } \\
\text { BC }(95,4 \%)\end{array}$ & $\begin{array}{l}\text { Datowanie } \\
\text { względne } \\
\text { zespołu wg } \\
\text { B. Gedigi* }\end{array}$ & $\begin{array}{c}\text { Data } \\
\text { w Modelu B } \\
\text { BC }(\mathbf{6 8 , 2 \%})\end{array}$ & $\begin{array}{c}\text { Data } \\
\text { w Modelu B } \\
\text { BC }(95,4 \%)\end{array}$ \\
\hline $\begin{array}{l}\text { No. of } \\
\text { grave }\end{array}$ & No. of lab. & $\begin{array}{c}\text { Date } \\
{ }^{14} \mathrm{C} \text { BP }\end{array}$ & $\begin{array}{c}\text { Calibrated } \\
\text { date BC } \\
(68,2 \%)\end{array}$ & $\begin{array}{c}\text { Calibrated } \\
\text { date BC } \\
(95,4 \%)\end{array}$ & $\begin{array}{c}\text { Relative } \\
\text { dating of } \\
\text { assemblage } \\
\text { after } \\
\text { B. Gediga* }\end{array}$ & $\begin{array}{c}\text { Date in } \\
\text { Model B } \\
\text { BC }(68,2 \%)\end{array}$ & $\begin{array}{c}\text { Date in } \\
\text { Model B } \\
\text { BC }(95,4 \%)\end{array}$ \\
\hline 10336 & Poz-96690 & $2285 \pm 30$ & $399-262$ & $405-213$ & LtA & $400-378$ & $405-362$ \\
\hline 8966 & Poz-96457 & $2455 \pm 30$ & $749-485$ & $756-413$ & HD & $549-428$ & $575-409$ \\
\hline 8893 & Poz- 85730 & $2465 \pm 30$ & $751-516$ & $764-430$ & $\mathrm{HC} / \mathrm{HD}$ & $735-490$ & $751-428$ \\
\hline
\end{tabular}


CHRONOLOGIA I PERIODYZACJA CMENTARZYSKA Z EPOKI BRĄZU I WCZESNEJ EPOKI ŻELAZA W DOMASŁAWIU

\begin{tabular}{|c|c|c|c|c|c|c|c|}
\hline 4417 & Poz-85723 & $2430 \pm 30$ & $727-414$ & $750-405$ & $\mathrm{HC} / \mathrm{HD}$ & $541-415$ & $744-404$ \\
\hline 12117 & Poz-85666 & $2540 \pm 30$ & $795-591$ & $799-547$ & $\mathrm{HC}$ & $797-600$ & $801-555$ \\
\hline 10821 & Poz- 85663 & $2675 \pm 30$ & $887-803$ & $896-800$ & $\mathrm{HC}$ & $831-806$ & $856-796$ \\
\hline 8956 & Poz-85732 & $2570 \pm 30$ & $802-766$ & $809-559$ & $\mathrm{HC}$ & $802-766$ & $810-561$ \\
\hline 8905 & Poz-85731 & $2545 \pm 30$ & $797-592$ & $801-549$ & $\mathrm{HC}$ & $797-591$ & $801-549$ \\
\hline 4271 & Poz-85722 & $2545 \pm 30$ & $797-592$ & $801-549$ & $\mathrm{HC}$ & $797-592$ & $801-550$ \\
\hline 4270 & Poz-85720 & $2500 \pm 30$ & $767-552$ & $788-537$ & $\mathrm{HC}$ & $767-558$ & $779-541$ \\
\hline 1693 & Poz-85716 & $2605 \pm 30$ & $810-786$ & $825-768$ & $\mathrm{HC}$ & $809-786$ & $824-768$ \\
\hline 818 & Poz-85715 & $2495 \pm 30$ & $763-550$ & $783-517$ & $\mathrm{HC}$ & $763-556$ & $776-539$ \\
\hline 390 & Poz-85714 & $2565 \pm 30$ & $802-761$ & $806-556$ & $\mathrm{HC}$ & $802-761$ & $808-556$ \\
\hline 369 & Poz-85713 & $2500 \pm 30$ & $767-552$ & $788-537$ & $\mathrm{HC}$ & $767-556$ & $780-541$ \\
\hline 366 & Poz-85712 & $2560 \pm 30$ & $801-599$ & $805-553$ & $\mathrm{HC}$ & $801-599$ & $806-556$ \\
\hline F 77 & Poz-92820 & $2775 \pm 35$ & $976-850$ & $1005-836$ & $\mathrm{VEB} / \mathrm{HC}$ & $973-855$ & $990-839$ \\
\hline F 213 & Poz-92816 & $2815 \pm 35$ & $1007-922$ & $1073-850$ & VEB & $981-916$ & $1010-856$ \\
\hline E 233 & Poz-92821 & $2815 \pm 35$ & $1007-922$ & $1073-850$ & VEB & $981-916$ & $1010-854$ \\
\hline B 225 & Poz-92855 & $2725 \pm 30$ & $897-836$ & $924-812$ & VEB & $900-840$ & $924-820$ \\
\hline В 106 & Poz-92861 & $2810 \pm 30$ & $1000-925$ & $1050-895$ & VEB & $978-918$ & $1009-895$ \\
\hline 3496 & Poz-85719 & $2725 \pm 30$ & $897-836$ & $924-812$ & VEB & $900-840$ & $925-820$ \\
\hline C 195 & Poz-92850 & $2935 \pm 35$ & $1210-1060$ & 1257-1019 & IV/VEB & $1210-1085$ & $1231-1018$ \\
\hline B 116 & Poz-92858 & $2870 \pm 30$ & $1110-1003$ & $1127-931$ & IV/VEB & $1107-1005$ & $1187-973$ \\
\hline F 212 & Poz-92817 & $2865 \pm 35$ & $1110-981$ & $1188-923$ & IV/VEB & $1110-994$ & $1187-923$ \\
\hline C 95 & Poz-92852 & $2940 \pm 30$ & $1213-1111$ & $1257-1044$ & IV/VEB & $1213-1110$ & $1232-1039$ \\
\hline B 144 & Poz-92856 & $2950 \pm 35$ & $1223-1112$ & $1264-1044$ & IV/VEB & $1222-1112$ & $1261-1048$ \\
\hline 12012 & Poz-85665 & $2825 \pm 30$ & $1011-929$ & $1071-902$ & IV/VEB & $1011-930$ & $1075-902$ \\
\hline 10140 & Poz-85733 & $2800 \pm 30$ & $996-915$ & $1027-848$ & IV/VEB & $994-915$ & $1026-849$ \\
\hline F 197 & Poz-92819 & $2930 \pm 35$ & $1196-1057$ & 1226-1014 & IVEB & $1196-1060$ & $1225-1016$ \\
\hline E 83 & Poz-92823 & $3065 \pm 35$ & $1393-1280$ & $1415-1230$ & IVEB & $1292-1229$ & 1319-1206 \\
\hline C 200 & Poz-92849 & $2925 \pm 30$ & $1192-1056$ & $1215-1022$ & IVEB & $1192-1057$ & $1215-1023$ \\
\hline C 97 & Poz-92851 & $2855 \pm 30$ & $1056-940$ & $1115-928$ & IVEB & $1070-985$ & $1121-968$ \\
\hline C 19 & Poz-92854 & $2865 \pm 30$ & $1109-996$ & $1123-930$ & IVEB & $1109-996$ & $1123-930$ \\
\hline 8428 & Poz-85726 & $2835 \pm 30$ & $1023-931$ & $1107-911$ & IVEB & $1025-931$ & $1086-911$ \\
\hline 8375 & Poz-85725 & $2835 \pm 30$ & $1023-931$ & $1107-911$ & IVEB & $1024-931$ & $1107-911$ \\
\hline B 85 & Poz-92862 & $2825 \pm 30$ & $1011-929$ & $1071-902$ & IVEB & $1039-975$ & $1107-949$ \\
\hline 5011 & Poz-85724 & $2840 \pm 30$ & $1043-936$ & $1108-917$ & IVEB & $1049-981$ & $1112-963$ \\
\hline
\end{tabular}




\begin{tabular}{|c|c|c|c|c|c|c|c|}
\hline F 222 & Poz-92815 & $3040 \pm 35$ & $1384-1231$ & $1410-1208$ & III/IVEB & $1283-1224$ & $1310-1131$ \\
\hline B 110 & Poz-92859 & $3040 \pm 35$ & $1384-1231$ & $1410-1208$ & III/IVEB & $1284-1225$ & $1310-1131$ \\
\hline E 110 & Poz-92822 & $3280 \pm 40$ & $1611-1516$ & $1658-1453$ & IIIEB & $1515-1434$ & $1547-1420$ \\
\hline E 27 & Poz-92824 & $3170 \pm 30$ & $1495-1416$ & $1505-1396$ & IIIEB & $1463-1412$ & $1500-1395$ \\
\hline D 11 & Poz-92848 & $3070 \pm 35$ & $1394-1285$ & $1419-1231$ & IIIEB & $1394-1298$ & $1416-1274$ \\
\hline C 162 & Poz-93156 & $3090 \pm 40$ & $1413-1298$ & $1437-1233$ & IIIEB & $1411-1303$ & $1432-1278$ \\
\hline B 109 & Poz-92860 & $3095 \pm 35$ & $1414-1302$ & $1432-1267$ & IIIEB & $1413-1306$ & $1431-1284$ \\
\hline B 64 & Poz-92863 & $3070 \pm 30$ & $1393-1287$ & $1415-1236$ & IIIEB & $1392-1299$ & $1412-1278$ \\
\hline 10162 & Poz-85735 & $3050 \pm 30$ & $1385-1263$ & $1401-1226$ & IIIEB & $1387-1286$ & $1405-1267$ \\
\hline 8659 & Poz-85729 & $3090 \pm 30$ & $1411-1302$ & $1427-1277$ & IIIEB & $1410-1304$ & $1423-1286$ \\
\hline 2892 & Poz-85718 & $3045 \pm 30$ & $1385-1236$ & $1399-1221$ & IIIEB & $1386-1282$ & $1401-1266$ \\
\hline 2835 & Poz-85717 & $3035 \pm 30$ & $1377-1231$ & $1397-1211$ & IIIEB & $1384-1278$ & $1398-1261$ \\
\hline E 220 & Poz-92864 & $3045 \pm 35$ & $1385-1235$ & $1409-1214$ & II/IIIEB & $1387-1285$ & $1407-1267$ \\
\hline
\end{tabular}

\section{ANALIZA BAYESOWSKA KALIBROWANYCH DAT ${ }^{14} \mathrm{C}$ PRÓBEK Z DOMASŁAWIA}

Znakomitym narzędziem dla wykorzystania informacji chronologicznej wypływającej z datowania ${ }^{14} \mathrm{C}$ serii próbek jest analiza bayesowska. Wykorzystując dodatkowe, niezależne od dat ${ }^{14} \mathrm{C}$, informacje chronologiczne, pozwala ona na ustalenie chronologii dokładniejszej od tej bazującej wyłącznie na wynikach datowania radiowęglowego (Bayliss 2015, 677-700). Wśród prac polskich badaczy w tej materii na uwagę zasługują m.in. opracowania serii dat ${ }^{14} \mathrm{C}$ z Catalhöyük w Turcji (Marciniak et al. 2015, 154-176), Bukivny na Ukrainie (Makarowicz, Goslar 2018, 40-51) czy Bronocic w Polsce (Kruk et al. 2018, 1-153).

$\mathrm{W}$ niniejszym opracowaniu wieki ${ }^{14} \mathrm{C}$ poszczególnych próbek wykalibrowano względem krzywej Intcal13 (Reimer et al. 2013, 1869-1887), przy użyciu program Oxcal v4.2.3 (Bronk Ramsey 2009, 337-360; Bronk Ramsey, Lee 2013, 720-730). Wyniki datowania względnego wykorzystano następnie jako informację a priori w bayesowskiej analizie całego zespołu dat. Przyjęto, że daty poszczególnych próbek winny mieścić się w następujących po sobie fazach, poczynając od najstarszej III EB, a kończąc na najmłodszej LtA, odpowiadającej okresowi lateńskiemu.
W pierwszym podejściu (Model A, ryc. 1A) założono, że groby o cechach przejściowych pochodzą $\mathrm{z}$ faz bezwzględnie rozdzielających zasadnicze okresy (np. każdy grób z fazy IV/V EB jest młodszy od każdego grobu z fazy IV EB oraz starszy od każdego grobu z fazy V EB). Wyniki modelowania bayesowskiego przy tym założeniu przedstawia ryc. 2. Wewnętrzna spójność tego modelu jest bardzo słaba, na co wskazuje wartość wskaźnika zgodności A (Bronk Ramsey 1995, 425-430), wynosząca Amodel:7, czyli zdecydowanie poniżej wartości 60 rekomendowanej przez Bronk Ramseya (1995, 428). Powodem niskiej wartości Amodel jest słaba zgodność dat niektórych próbek z modelem. Datami o niskich współczynnikach zgodności (ryc. 2) są tu daty z grobów C195, C95 i B144 (faza IV/V EB, odpowiednio A:44, A:30 i A:26), wszystkie starsze od dat innych grobów z tej fazy, daty z grobów E83, 8428, 8375, B85 i 5011 (faza IV EB, odpowiednio A:38, A:29, A:29, A:17 i A:37), a także daty z grobów E110 i E220 (faza III EB, A:6, oraz faza II/III $\mathrm{EB}, \mathrm{A}: 10)$.

Słaba zgodność dziesięciu dat z modelem nie oznacza, że wszystkie te daty są niereprezentatywne. Przykładowo, niezgodność dat próbek z pochówków C195, C95, B144, E83, 8428, 8375, B85 oraz 5011 jest spowodowana tym, że kalibrowane daty ${ }^{14} \mathrm{C}$ pierwszych trzech próbek z tej grupy (faza IV/V EB) są najprawdopodobniej starsze od kalibrowanych dat pozostałych pięciu (faza IV EB), 


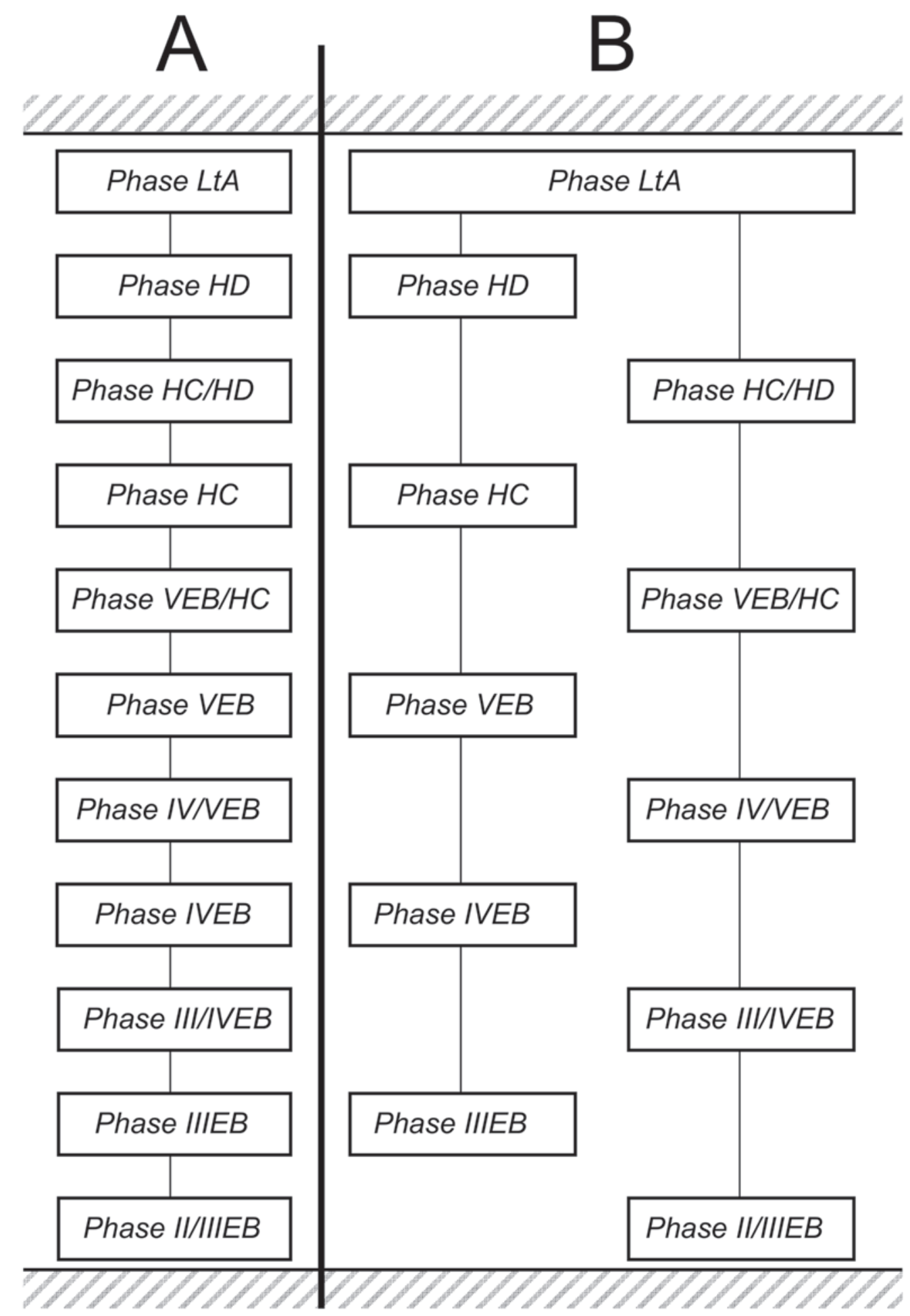

Ryc. 1. Modele sekwencji czasowej faz chronologii względnej grobów z Domasławia, wykorzystane w bayesowskim opracowaniu wyników datowania radiowęglowego przedstawionych w niniejszej pracy

Fig. 1. Models of the chronological sequence of relative chronology phases from Domasław, used in Bayesian analysis of radiocarbon dating results presented in this work

podczas gdy datowanie względne, przy założeniu chronologicznego modelu A, sugeruje przeciwne następstwo dat tych próbek. W efekcie, usunięcie $\mathrm{z}$ modelu jednej lub drugiej podgrupy próbek auto- matycznie likwidowałoby niezgodność dat drugiej podgrupy próbek z modelem. Podobna niezgodność dotyczy próbek E110 (faza III EB) i E220 (faza II/III EB). 


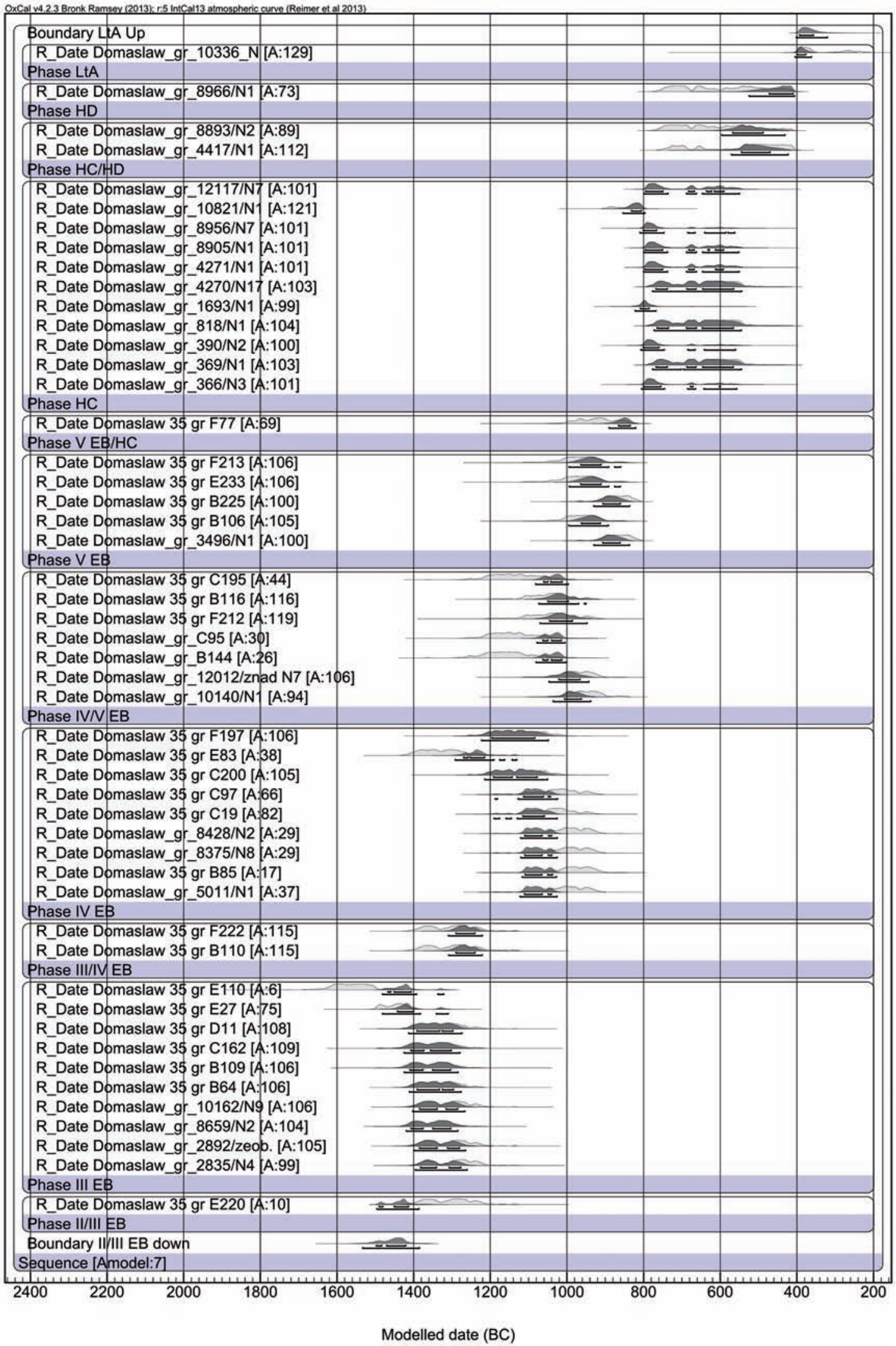

Ryc. 2. Analiza bayesowska zespołu dat próbek kości z Domasławia, przy założeniu chronologicznego modelu A (ryc. 1A). Sylwety szare reprezentują rozkłady prawdopodobieństwa kalibrowanych dat próbek niezależnych, zaś sylwety czarne reprezentują rozkłady prawdopodobieństwa dat próbek związanych modelem

Fig. 2. Bayesian analysis of the set of dates of bone samples from Domasław, assuming the chronological model A (Fig. 1A). Grey profiles represent the probability distributions of calibrated dates of independent samples,

while black profiles represent the probability distributions of dates of the samples associated with the model 


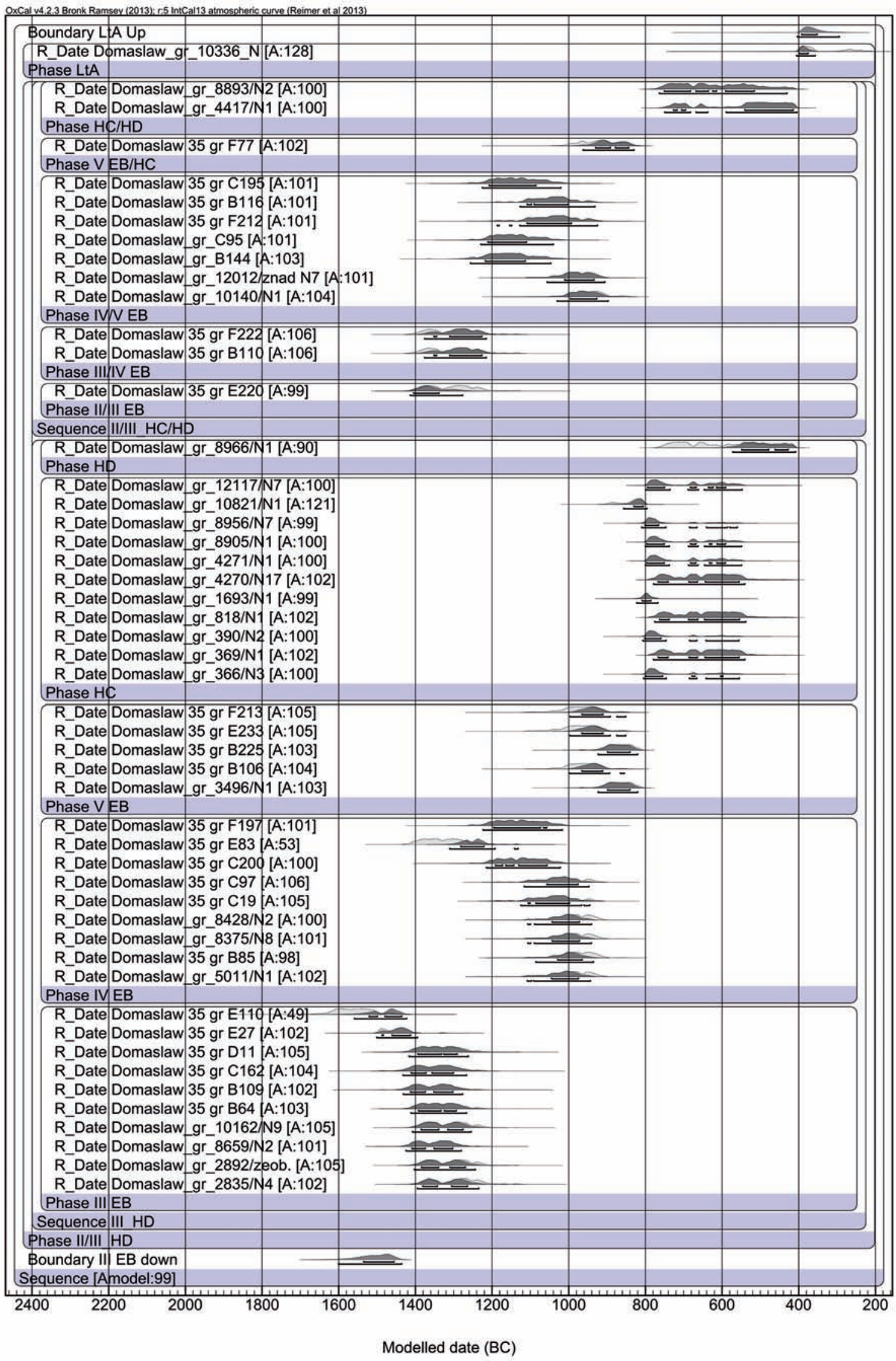

Ryc. 3. Analiza bayesowska zespołu dat próbek kości z Domasławia, przy założeniu chronologicznego modelu B (ryc. 1B)

Fig. 3. Bayesian analysis of the set of dates of bone samples from Domasław, assuming the chronological model B (Fig. 1B) 
Powyższe spostrzeżenia każą zrewidować założenie modelu chronologicznego. W zrewidowanym modelu (Model B, ryc. 1B) założono, że groby z wyposażeniem o cechach dwóch następujących po sobie okresów mogą być równowiekowe z grobami $\mathrm{z}$ jednego lub drugiego okresu. To założenie jest znacznie bardziej rozsądne od założenia modelu A, gdyż nie ma wątpliwości, że zmiany cech stylistyki przedmiotów wytwarzanych przez człowieka (które, stanowiąc wyposażenie badanych dziś grobów, są podstawą datowania względnego) miały charakter płynny i przedmioty z elementami stylistyki dwóch kolejnych okresów mogły być wytwarzane w tym samym czasie co przedmioty o cechach charakterystycznych dla jednego czy drugiego okresu. Analiza bayesowska modelu B daje bardzo dobry wskaźnik zgodności (Amodel:97), zdecydowanie potwierdzając jego słuszność, w opozycji do „sztucznie sztywnego” modelu A.

\section{RAMY CHRONOLOGICZNE PERIODYZACJI PÓŹNEJ EPOKI BRĄZU I WCZESNEJ EPOKI ŻELAZA NA STANOWISKU W DOMASŁAWIU}

Analiza bayesowska, oprócz uściślenia informacji o datach poszczególnych próbek, pozwala określić wieki bezwzględne przedziałów czasu odpowiadających kolejnym fazom modelu (w tym przypadku: okresom chronologii względnej). Wyniki datowania okresów rozpoznanych w datowaniu względnym grobów z Domasławia (Gediga 2019, w tym tomie) przedstawia Tabela 2.

Wyznaczone modelami $68 \%$ przedziały poszczególnych okresów przedstawiono też na rycinie 4. Trzeba zwrócić uwagę, że dokładność wyznaczenia ram chronologicznych jest dla różnych okresów różna. W szczególności, najmłodsze dwa okresy (HD i LtA) są w Domasławiu reprezentowane tylko przez pojedyncze próbki, tak więc zakreślone w Tabeli 2 ramy czasowe tych okresów trzeba traktować jako orientacyjne. Z drugiej strony, na okres HC, w radiowęglowej krzywej kalibracyjnej przypada tzw. plateau halsztackie, oznaczające, że wieki ${ }^{14} \mathrm{C}$ materiałów uformowanych kiedykolwiek między ok. 750 a 400 BC są wszystkie niemal takie same (por. ryc. 6). $Z$ tego powodu precyzyjne określenie kalibrowanych dat ${ }^{14} \mathrm{C}$ próbek jest zawsze trudne.

Porównanie otrzymanych tu wyników modelowania $\mathrm{z}$ chronologicznymi ramami systemu J. Kostrzewskiego opublikowanymi przez J. Dąbrowskiego $(2009,17$, tab. 1) i reprodukowanymi w późniejszej publikacji B. Gedigi (2013, 383, tab. 1) wskazuje (ryc. 4), że zgodność modelu z Domasławia ze schematem J. Dąbrowskiego (2009, 17, tab. 1) dotyczy tylko najmłodszej granicy HD - LtA. Wszystkie wcześniejsze okresy w modelach z Domasławia wyglądają o 100-200 lat postarzone w stosunku do schematu J. Dąbrowskiego, przy czym postarzenie to jest tym większe, im starszych okresów dotyczy. Ciekawe, że w analizowanym wycinku przeszłości w podobny sposób zmienia się różnica między wiekiem kalendarzowym (cal BP) a wiekiem radiowęglowym $\left({ }^{14} \mathrm{C} \mathrm{BP}\right)$.

Tabela 2. Daty kalendarzowe faz odpowiadanych okresom rozpoznanym w datowaniu względnym grobów z Domasławia.

Table 2. Calendar dates of phases corresponding to periods recognised in relative dating of graves from Domasław.

\begin{tabular}{|c|c|c|c|}
\hline Okres & Liczba dat & $\begin{array}{l}\text { Przedzial } 68 \% \\
\text { cal BC }\end{array}$ & $\begin{array}{l}\text { Przedzial 95\% } \\
\text { cal BC }\end{array}$ \\
\hline Period & Number of dates & $\begin{array}{l}\text { Interval } 68 \% \\
\quad \text { cal BC }\end{array}$ & $\begin{array}{l}\text { Interval 95\% } \\
\text { cal BC }\end{array}$ \\
\hline LtA & 1 & $400-376$ & $406-358$ \\
\hline $\mathrm{HD}$ & 1 & $549-428$ & $575-409$ \\
\hline $\mathrm{HC}$ & 11 & $820-580$ & $856-476$ \\
\hline V EB & 5 & $945-844$ & $981-816$ \\
\hline IV EB & 9 & 1218-1001 & $1277-955$ \\
\hline III EB & 10 & $1458-1285$ & $1527-1233$ \\
\hline
\end{tabular}




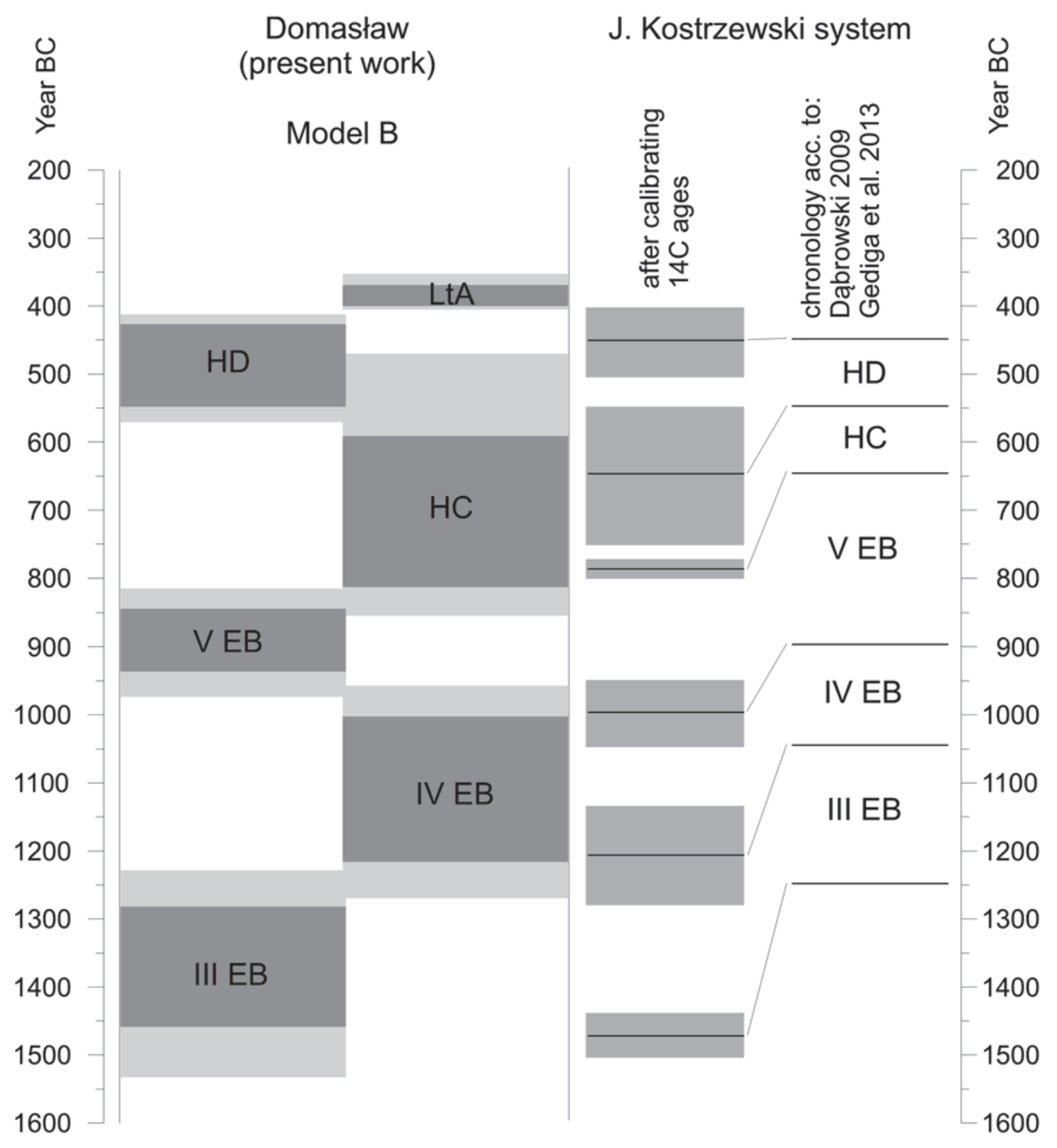

Ryc. 4. Przedziały dat faz reprezentujących okresy rozpoznane w datowaniu względnym grobów z Domasławia.

Ciemniejsze i jaśniejsze prostokąty reprezentują odpowiednio 68\% i 95\% przedziały dat poszczególnych faz.

Dla porównania przedstawiono schemat chronologiczny opublikowany przez J. Dąbrowskiego (2009) i reprodukowany przez B. Gedigę (2013) oraz schemat zmodyfikowany przy założeniu, że wieki w schemacie oryginalnym były określone bez uwzględnienia kalibracji radiowęglowej skali czasu

Fig. 4. Intervals of phases dates representing periods recognized in relative dating of graves from Domasław. Darker and lighter rectangles represent $68 \%$ and $95 \%$ of the date intervals of individual phases, respectively. For comparison, a chronological diagram published by J. Dąbrowski (2009) and reproduced by B. Gediga (2013) is presented, as well as a modified scheme assuming that the dates in the original scheme were determined without taking into account the calibration of the radiocarbon time scale

Różnica ta (ryc. 5), przekraczająca 200 lat ok. roku $1500 \mathrm{BC}$, zmniejsza się do ok. 100 lat ok. roku 1000 BC i do zera ok. roku 500 BC. Nasuwa się więc wątpliwość, czy Dąbrowski (2009, 17, tab. 1) w konstrukcji schematu chronologicznego nie prze- liczył lat radiowęglowych BP na lata kalendarzowe BC przez proste odjęcie 1950 (wiek BP jest liczony względem roku $1950 \mathrm{AD}$ ), ignorując kształt krzywej kalibracyjnej? Niestety, publikacja J. Dąbrowskiego ma charakter popularny i przedstawiony tam 


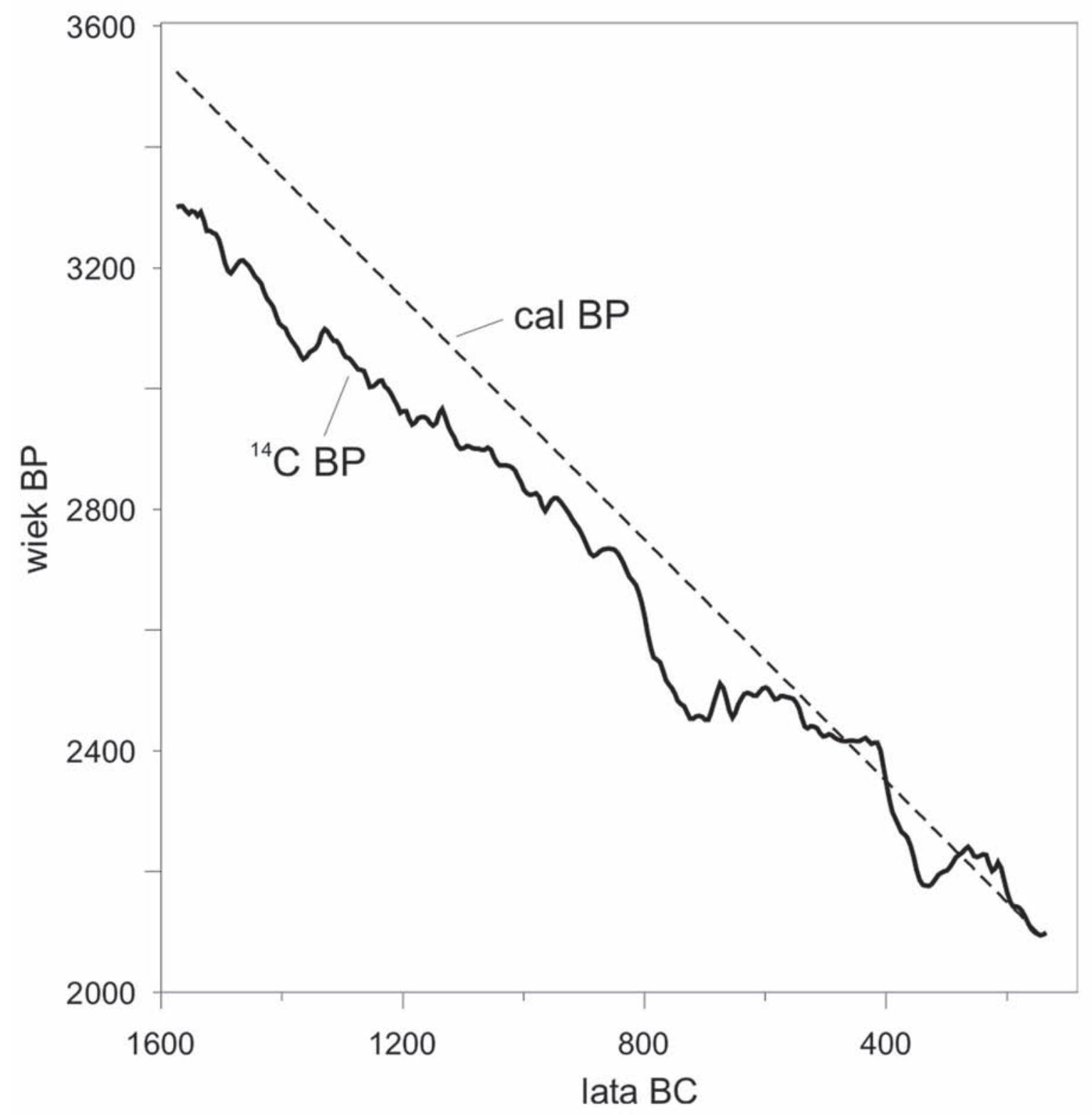

Ryc. 5. Porównanie wieku radiowęglowego $\left({ }^{14} \mathrm{C}\right.$ BP, Reimer et al. 2013) i kalendarzowego (cal BP) w okresie 1600-200 BC

Fig. 5. Comparison of radiocarbon age $\left({ }^{14} \mathrm{C} \mathrm{BP}\right.$, Reimer et al. 2013) and calendar age (cal BP) in the period $1600-200 \mathrm{BC}$

Na sąsiedniej stronie (On next page):

Ryc. 6. Kalibrowane daty ${ }^{14} \mathrm{C}$ próbek z Domasławia (niniejsza praca) i Kietrza (Chochorowski 2007), pobranych z grobów datowanych archeologicznie na okresy od II/III EB do LtA. Dla uproszczenia, na rysunku pominięto domasławskie daty z grobów wykazujących cechy dwóch kolejnych okresów. Zróżnicowanie dat z Kietrza W zależności od frakcji użytej do pomiaru ${ }^{14} \mathrm{C}$ (wg Chochorowski 2007), przedstawiono przed numerami laboratoryjnymi Ki-, w formie symboli: WD - węgiel drzewny, WK - węgiel kostny, WM - węgiel masowy Fig. 6. Calibrated 14C dates of samples from Domasław (this work) and Kietrz (Chochorowski, 2007), taken from archaeologically dated graves to periods from II/III EB to LtA. For simplicity, the figure omits Domasław dates from graves with the characteristics of two subsequent periods. Diversity of dates from Kietrz depending on the fraction used to measure 14C (after Chochorowski, 2007), was presented before the laboratory numbers $\mathrm{Ki}$-, in the form of symbols: WD - charcoal, WK - bone coal, WM - mass coal 


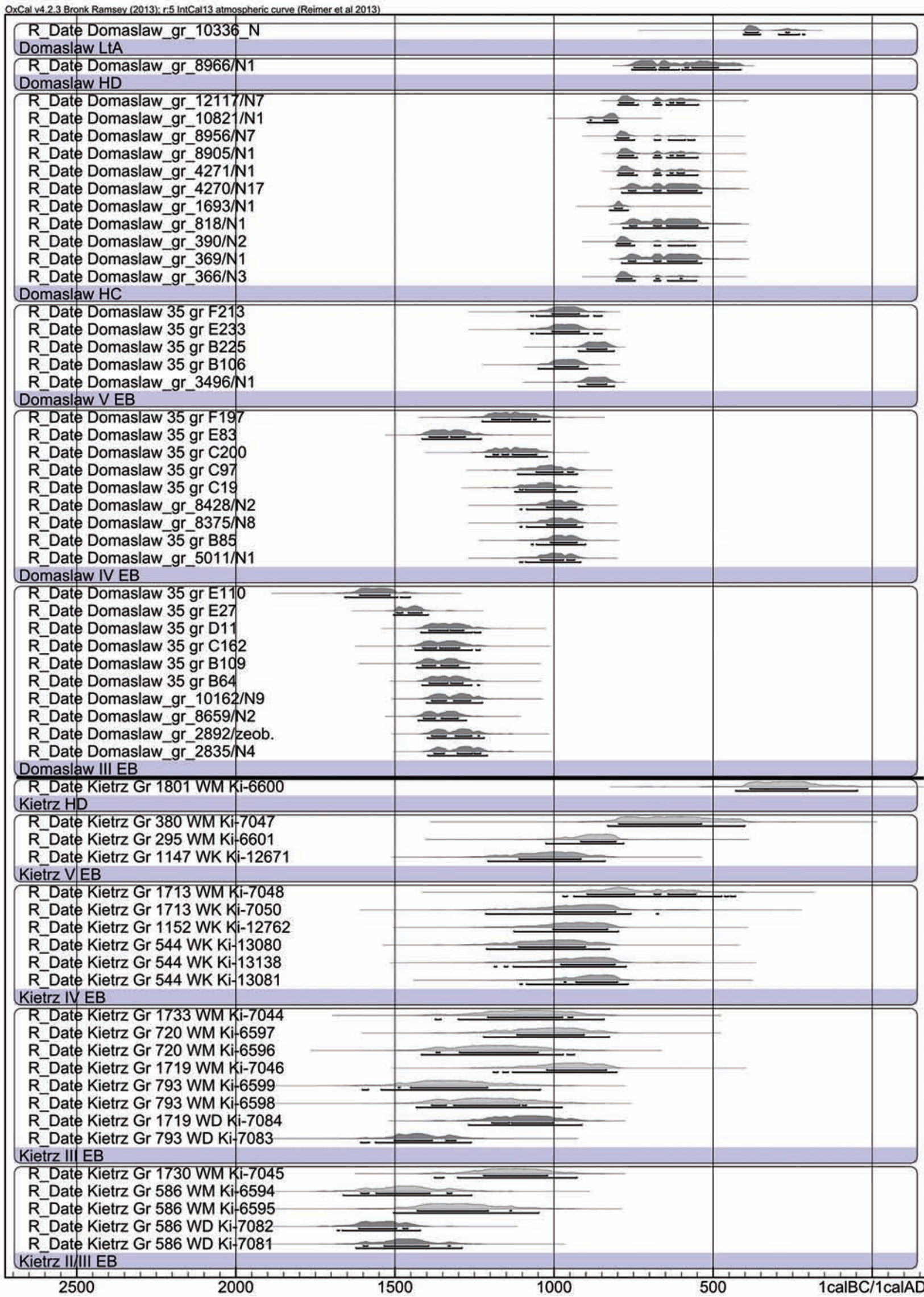


schemat chronologiczny trudno przeanalizować w oparciu o obecny stan wiedzy w sposób ścisły.

Jeśli opublikowany przez J. Dąbrowskiego (2009, 17, tab. 1) schemat chronologiczny w istocie przedstawia wieki radiowęglowe pomniejszone o 1950, jego poprawa sprowadzałaby się do kalibracji tychże wieków. Tak ,poprawiony” schemat (ryc. 4) nieźle zgadzałby się z ramami chronologicznymi wynikającymi z badań grobów z Domasławia, generalnie wzmacniając wiarygodność tych ostatnich.

\section{PORÓWNANIE WYNIKÓW DATOWANIA ${ }^{14} \mathrm{C}$ GROBÓW CIAŁOPALNYCH Z DOMASŁAWIA I KIETRZA}

Pokaźna seria dat radiowęglowych z tego samego okresu co w Domasławiu została wcześniej uzyskana w badaniach grobów ciałopalnych z cmentarzyska w niedalekim Kietrzu (Chochorowski 2007, 103-138). W tamtych badaniach radiowęglowe datowanie kości z użyciem kolagenu (wypalonego wskutek kremacji) również nie było możliwe i do analizy radiowęglowej używano frakcji tzw. „węgla kostnego" lub „węgla masowego” (węglanowego). Datowania radiowęglowe były wykonane techniką radiometryczną w Laboratorium ${ }^{14} \mathrm{C}$ w Kijowie. Opis zastosowanej w tamtych badaniach preparatyki kości (Chochorowski 2007, 104-107) jest raczej ogólnikowy; można się domyślać, że frakcja „węgla kostnego" to węgiel organiczny, pozostały po usunięciu węglanów wskutek traktowania roztworem $\mathrm{HCl}$ oraz usunięciu kwasów huminowych w kąpieli w roztworze $\mathrm{NaOH}$, natomiast „węgiel masowy" to suma resztek węgla organicznego oraz węgla związanego z frakcją węglanową. Dodatkowo, w badaniach grobów w Kietrzu datowano kilka próbek węgla drzewnego.

Jak zauważa J. Chochorowski $(2007,106)$, daty ${ }^{14} \mathrm{C}$,węgla masowego" mogą być odmłodzone, głównie węglanem wapnia wytrącanym z jonów węglanowych niesionych przez wody gruntowe. Ten efekt, zauważony przez J. Chochorowskiego (2007, 106), zilustrowano na rycinie 6, na której kalibrowane daty z Kietrza (o numerach laboratoryjnych Ki-), uzyskane z użyciem frakcji „,węgla masowego", są systematycznie młodsze od dat pochodzących z tych samych okresów próbek, „węgla kostnego" czy też węgli drzewnych.

Jak pokazują badania J.N. Lantinga i J. Van der Plichta (2001, 249-254), zafałszowania daty radiowęglowej kości poddanych kremacji w wysokiej temperaturze można uniknąć, usuwając resztki frakcji organicznej oraz rozkładając ziarna wtórnego węglanu i do pomiaru ${ }^{14} \mathrm{C}$ biorąc tylko węgiel uwolniony $\mathrm{z}$ pozostałej frakcji apatytowej. Taką właśnie preparatykę stosowano, datując kości z Domasławia w niniejszej pracy (patrz rozdział: „Metodyka i wyniki datowania..."). Uzyskane w ten sposób kalibrowane daty ${ }^{14} \mathrm{C}$ kości z Domasławia są wyraźnie starsze od dat ${ }^{14} \mathrm{C}$,węgla masowego" pochodzących z tych samych okresów kości z Kietrza (ryc. 6) i z pewnością są bardziej poprawne. Rzecz jasna, ilości węgla uzyskiwanego z frakcji apatytowej są bardzo małe, dając szansę pomiaru ${ }^{14} \mathrm{C}$ tylko przy użyciu niedostępnej laboratorium kijowskiemu techniki AMS.

W zespole dat ${ }^{14} \mathrm{C}$ z Kietrza, bardziej zbliżone do dat domasławskich (z tych samych okresów), są te otrzymane dla frakcji „węgla kostnego" (ryc. 6). W szczególności, data z grobu 1147 w Kietrzu (Ki-12671) z okresu V EB wypada w środku fazy „V EB” datowanej próbkami z Domasławia, natomiast daty grobów 1713, 1152 i 544 w Kietrzu (Ki7050, Ki-12762, Ki-13080, Ki-13138 i Ki13081), wprawdzie średnio rzecz biorąc młodsze od domasławskich dat fazy „IV EB”, nie wykraczają istotnie poza przedział czasu wyznaczony dla tej fazy w Domasławiu. Niemniej jednak trzeba zwrócić uwagę, że nie wiadomo, czy „węgiel kostny” kości z Kietrza był związany wyłącznie z kolagenen (frakcją kości najlepiej nadającą się do datowania), czy też zawierał inne grupy związków. Ponadto, nawet jeśli datując „węgiel kostny” kości z Kietrza zastosowano ekstrakcję kolagenu, niemal z pewnością nie zastosowano ultrafiltracji (możliwej praktycznie do wykonania tylko dla porcji miligramowych, nadających się do pomiaru ${ }^{14} \mathrm{C}$ jedynie techniką AMS). Pominięcie ultrafiltracji (Bronk Ramsey et al. 2004, 155-163; Brock et al. 2010, 106-107) stwarza niebezpieczeństwo zafałszowania daty ${ }^{14} \mathrm{C}$ obecnością atomów „młodszego” węgla, przyłączonego do końców krótkich łańcuchów aminokwasowych, powstałych w wyniku degradacji cząsteczek oryginalnego kolagenu. Wydaje się, że przeciętnie młodszy wiek próbek dat „węgla kostnego” z Kie- 
trza w stosunku do dat fazy „IV EB” z Domasławia może być właśnie skutkiem niezastosowania ultrafiltracji kolagenu.

W publikacji dotyczącej datowania grobów z cmentarzyska w Kietrzu J. Chochorowski (2007, 130-132) zawarł wniosek, iż „we wczesnołużyckiej populacji, użytkującej cmentarzysko w Kietrzu, różne tradycje kulturowe mogły być kultywowane równolegle”. W świetle dyskusji na temat poprawności radiowęglowych dat próbek z tamtego stanowiska (a również biorąc pod uwagę duże niepewności laboratoryjne kijowskich oznaczeń wieku), powyższy wniosek można by uznać za dość słabo udokumentowany. Jednak wniosek ten znajduje silne poparcie w datowaniu grobów z Domasławia, w których z dwóch modeli chronologicznych (A i B, ryc. 1) do przyjęcia okazał się tylko ten zakładający równoległe powstawanie grobów z wyposażeniem o cechach charakterystycznych dla danego okresu oraz cechach charakterystycznych dla dwóch okresów.

\section{EFEKT REZERWUAROWY}

Wyznaczając ramy chronologiczne na podstawie datowania ${ }^{14} \mathrm{C}$ kości ludzkich, trzeba pamiętać o możliwości zafałszowania wyników, spowodowanego efektem rezerwuarowym. Efekt rezerwuarowy, występujący, jeśli znaczący udział w diecie datowanych osobników miał pokarm pochodzenia wodnego (ryby, skorupiaki), może powodować postarzenie wieku ${ }^{14} \mathrm{C}$ nawet o setki lat (np. Olsen et al. 2010, 635-644; Shishlina et al. 2014, 767-778). Stwierdzenie udziału takiego pokarmu w diecie datowanego osobnika wymaga analizy składu izotopów stabilnych węgla $\left(\delta^{13} \mathrm{C}\right)$, a przede wszystkim azotu $\left(\delta^{15} \mathrm{~N}\right)$ w kolagenie wyekstrahowanym z kości (np. Pospieszny, Bełka 2015, 197-218; Goslar et al. 2017, 64-90). Niestety, brak kolagenu w badanych kościach wyklucza możliwość przeprowadzenia takiej analizy, tak w Domasławiu, jak i w Kietrzu. Tak więc w tym aspekcie analizy chronologii grobów ciałopalnych z Domasławia skazani jesteśmy na niepewność.

\section{BIBLIOGRAFIA}

Bayliss A. (2015). Quality in Bayesian chronological models in archaeology. World Archaeology, 47(4), 677700 .

Brock F., Higham T., Ditchfield P., Bronk Ramsey C. (2010). Current pretreatment methods for AMS radiocarbon dating at the Oxford Radiocarbon Accelerator Unit (ORAU). Radiocarbon, 52, 103-112.

Bronk Ramsey C. (1995). Radiocarbon calibration and analysis of stratigraphy: the OxCal program. Radiocarbon, 37, 425-430.

Bronk Ramsey C. (2009). Bayesian analysis of radiocarbon dates. Radiocarbon, 51, 337-360.

Bronk Ramsey C., Higham T., Bowles A., Hedges R.E.M. (2004). Improvements to the pretreatment of bone at Oxford. Radiocarbon, 46, 155-163.

Bronk Ramsey C., Lee S. (2013). Recent and Planned Developments of the Program OxCal. Radiocarbon, 55, 720-730.

Chochorowski J. (2007). Metodyczne i metodologiczne problemy datowania radiowęglowego pozostałości kremacji z grobów ciałopalnych kultury łużyckiej (na przykładzie materiałów z cmentarzyska w Kietrzu). W: J. Chochorowski (red.), Studia nad epoka brazu i wczesna epoka żelaza w Europie (103-138). Kraków: Wydawnictwo Uniwersytetu Jagiellońskiego.

Dąbrowski J. (2009). Polska przed trzema tysiacami lat. Czasy kultury tużyckiej (Poland three thousand years ago: the Lusatian Culture and his times). Warszawa: Wydawnictwo „Trio”.

Gediga B. (1982). Zagadnienia periodyzacji okresu rozwoju kultury łużyckiej w świetle kontaktów z Południem. W: M. Gedl (red.), Południowa strefa kultury tużyckiej i powiązania tej kultury z Południem (49-59). KrakówPrzemyśl: Materiały z konferencji, która odbyła się w Krakowie, Nowej Hucie i Nowym Sączu w dniach od 11 do 14 IV $1978 \mathrm{r}$.

Gediga B. (2013). The Culture of the Early Iron Age in the South-Western Regions of Poland in the Light of New Research. W: S. Bergebrant, S. Sabatini (red.), Counterpoint: Essays in Archaeology and Heritage Studies in Honour of Professor Kristian Kristiansen (383399). BAR International Series 2508, Archeopress. 
Gediga B. (2019). Uwagi do datowania i periodyzacji użytkowania cmentarzyska w Domasławiu- Chrzanowie, pow. wrocławski. Przegląd Archeologiczny, 67, w tym tomie.

Goslar T., Czernik J., Goslar E. (2004). Low-energy ${ }^{14} \mathrm{C}$ AMS in Poznan Radiocarbon Laboratory, Poland. Nuclear Instruments and Methods in Physics Research B, 223-4, 5-11.

Goslar T., Jankowski M., Kośko A., Lityńska-Zając M., Włodarczak P., Żurkiewicz D. (2017). Builders and users of ritual centres, Yampil Barrow Complex: studies of diet based on stable carbon and nitrogen isotope composition. W: A. Kośko (red.), Podolia „Barrow Culture" communities: 4th/3rd mill. BC. The Yampil Complex: interdisciplinary studies (64-90). BalticPontic Studies, 22.

Kostrzewski J. (1948). Od mezolitu do okresu wędrówek ludów. W: S.W. Krukowski (red.), Prehistoria ziem polskich. Kraków: Nakładem Polskiej Akademii Umiejętności.

Kostrzewski J., Chmielewski W., Jażdżewski K. (1965). Pradzieje Polski (Prehistorie de la Pologne). Warszawa: Zakład im. Ossolińskich.

Kruk J., Milisauskas S., Włodarczak P. (2018). Real time. Radiocarbon dates and bayesian analysis of the neolithic settlement at Bronocice, fourth millennium BC. Kraków: Instytut Archeologii i Etnologii PAN.

Lanting J.N., Van der Plicht J. (2001). Dating of cremated bones. Radiocarbon, 43, 249-254

Longin R. (1971). New method of collagen extraction for radiocarbon dating. Nature, 230, 241-242.

Makarowicz P., Goslar T., Niebieszczański J., Cwaliński M., Kochkin I.T., Romaniszyn J., Lysenko S.D., Ważny T. 2018. Middle Bronze Age societies and barrow line chronology. A case study from the Bukivna 'necropolis', Upper Dniester Basin, Ukraine. Journal of Archaeological Science, 95, 40-51, doi: 10.1016/j.jas. 2018.04.010.

Marciniak A., Barański M.Z., Bayliss A., Czerniak L., Goslar T., Southon J., Taylor R.E. (2015). Fragmen- ting times: interpreting a Bayesian chronology for the Late Neolithic occupation of Catalhöyük, East Turkey. Antiquity, 89(343), 154-176.

Olsen J., Heinemeier J., Lübke H., Lüth F., Terberger T. (2010). Dietary habits and freshwater reservoir effects in bones from a Neolithic ME Germany cemetery. Radiocarbon, 53, 635-644.

Pospieszny Ł., Bełka Z. (2015). Dieta i mobilność u schyłku starożytności. Szczątki ludzkie z cmentarzyska w Karczynie/Witowach stan 21/22 w świetle badań izotopowych. W: J. Bednarczyk, A. Romańska (red.), Karczyn/Witowy stan. 21/22. Birytualne cmentarzysko kultury przeworskiej z Kujaw (197-218). Studia i Materiały do Dziejów Kujaw 12. Poznań-Inowrocław.

Reimer P.J., Bard E., Bayliss A., Beck W.J., Blackwell P.G., Bronk-Ramsey C., Buck C.E., Cheng H., Edwards R.L., Friedrich N., Grootes P.M., Guilderson T.P., Hafidason Hafifi, Hajdas I., Hattè C., Heaton T.J., Hoffmann D.L., Hogg A.G., Hughen K.A., Kaiser K.F., Kromer B., Manning S.V., Niu M., Reimer R.W., Richards D.A., Scott E.M., Southon J.R., Staff R.A., Turney S.M., Van der Plicht J. (2013). IntCal13 and marine 13 Radiocarbon age calibration curves 0-50,000 years cal BP. Radiocarbon, 55, 1869-1887.

Shishlina N., Sevastyanov V., Zazovskaya E., van der Plicht J. (2014). Reservoir effect of archaeological samples from steppe bronze age cultures in southern Russia. Radiocarbon, 56, 767-778.

van Klinken G.J. (1999). Bone collagen quality indicators for palaeodietary and radiocarbon measurements. Journal of Archaeological Science, 26, 687-695.

Zazzo A., Saliège J.F., Person A., Boucher H. (2009). Radiocarbon dating of calcined bones: where does the carbon come from? Radiocarbon, 51, 601-611.

Zazzo A., Lebon M., Chiotti L., Comby C., Delqué-Količ E., Nespoulet R., Reiche I. (2013). Can we use calcined bones for ${ }^{14} \mathrm{C}$ dating the Paleolithic? Radiocarbon, 55, 1409-1421. 


\section{THE CHRONOLOGY AND PERIODIZATION OF THE BRONZE AND THE EARLY IRON AGE BURIAL GROUND IN DOMASŁAW, WROCŁAW DISTRICT, BASED ON RADIOCARBON DATING}

\section{Methodology and results of radiocarbon dating of the bones from Domaslaw}

Bone samples from 50 cremation graves found at the site in Domasław were selected for radiocarbon dating (the programme was implemented as part of the National Science Centre's project 'Transformations in the burial rite in the Bronze Age and the early Iron Age as an expression of socio-cultural changes in south-western Poland' - contract No. UMO-2014/15/B/HS3/02463 signed on 10.08.2015). The bones were dated using the AMS technique (accelerator mass spectrometry) at the Poznań Radiocarbon Laboratory (Goslar et al. 2004). As a result of the cremation of the bodies, in none of the bone samples (except the youngest one) has collagen been preserved, the substance most often used in the radiocarbon dating of this material.

Extraction of collagen from the youngest sample (from grave 10336) was carried out using the standard Longin method (1971) with the additional use of $\mathrm{NaOH}$ to remove humic acids, and ultrafiltration (Bronk Ramsey et al. 2004; Brock et al. 2010) to remove shorter amino acid chains resulting from collagen degradation in bones lying in sediment. The satisfactory quality of the obtained collagen (extraction yield $0.7 \%$ ) was confirmed by the result of measuring the $\mathrm{C} / \mathrm{N}$ ratio (3.33), which is within the generally accepted admissibility range (van Klinken 1999).

In the case of other bones, their nearly white colour indicated a high burning temperature, exceeding $600^{\circ} \mathrm{C}$ (i.e. calcination). Research of Lanting et al. (2001) showed that, during the calcination process, recrystallization occurs of apatite, the grains of which become larger and better packed than in the apatite of bones of a living individual. As a result, apatite becomes more resistant to the exchange of carbon with the environment, thanks to which it can be isolated from the less resistant secondary calcite, crystallized in the bone after it has been deposited in the sediment. Therefore, the pretreatment of such ${ }^{14} \mathrm{C}$ dating materials includes the removal of organic fraction residues (by treatment with $\mathrm{NaClO}_{2}$ ) and the removal of possible secondary calcite (by treatment with $\mathrm{CH}_{3} \mathrm{COOH}$ ), and only after these steps is the apatite leached to release the carbon designated for ${ }^{14} \mathrm{C}$ measurement.

As evidenced by later research (Zazzo et al. 2009; 2013), during calcination, carbon exchange with the environment may occur, including $\mathrm{CO}_{2}$ contained in the air and $\mathrm{CO}_{2}$ generated during the combustion of cremation fuel.
Such processes could influence the result of radiocarbon dating if old bones underwent calcination (if cremation was carried out long after the death of individuals), or if the fuel was wood that was very old at the time of cremation (or hard coal). In the case of the bones from graves in Domasław, this problem is unlikely.

The results of ${ }^{14} \mathrm{C}$ dating are shown in Table 1 . The samples in Table 1 are arranged based on relative dating (Gediga 1982; 2019), made on the basis of the characteristic features of grave goods. The symbols of particular periods in the Table correspond to the division of the late Bronze Age and the Hallstatt period proposed a long time ago by J. Kostrzewski (1948), and cited in numerous subsequent publications (e.g. Kostrzewski et al. 1965; Dąbrowski 2009; Gediga 2013). In the relative dating of graves from Domasław (Gediga, in this volume), which assigns them to the periods of the system by J. Kostrzewski, (III, IV and V in the late Bronze Age, HC and HD in the Hallstatt period), graves with transitional features attributable to both subsequent periods, i.e. II/III EB, III/IV EB, IV/V EB, V EB/HC and $\mathrm{HC} / \mathrm{HD}$ were distinguished.

\section{Bayesian analysis of the calibrated ${ }^{14} \mathrm{C}$ dates of samples from Domasław}

Bayesian analysis is a great tool for the use of chronological information from the ${ }^{14} \mathrm{C}$ dating of a sample series. By using additional chronological information independent of the ${ }^{14} \mathrm{C}$ dates, it allows us to establish a more accurate chronology than what is based solely on the results of radiocarbon dating (Bayliss 2015, 677-700). Amongst the works of Polish researchers in this matter that deserve attention are the studies of the ${ }^{14} \mathrm{C}$ dates series from Catalhöyük in Turkey (Marciniak et al. 2015, 154-176), Bukivna in Ukraine (Makarowicz and Goslar 2018, 40-51) and Bronocice in Poland (Kruk et al. 2018, 1-153).

In this paper, the ${ }^{14} \mathrm{C}$ dates of individual samples were calibrated according to the Intcal13 curve (Reimer et al. 2013) using the Oxcal v4.2.3 program (Bronk Ramsey 2009; Bronk Ramsey and Lee 2013). The relative dating results were then used as a priori information in the Bayesian analysis of the whole set of dates. It was assumed that the dates of individual samples should fall into successive phases, beginning with the oldest III EB, and ending with the youngest LtA, corresponding to the La Tène period. 
In the first approach (Model A, Fig. 1A) it was assumed that graves with transitional features come from the phases absolutely separating the basic periods (e.g. each grave from phase IV/V EB is younger than each grave from phase IV EB and older than each grave from phase V EB). The results of Bayesian modelling in this assumption are presented in Fig. 2. The internal coherence of this model is very weak, which is indicated by the value of the agreement index A (Bronk Ramsey 1995), amounting to Amodel: 7, i.e. well below the 60 recommended by Bronk Ramsey (1995). The reason for the low Amodel value is the poor match of the dates of some samples with the model. The dates with low compliance indicators (Fig. 2) are dates from graves C195, C95 and B144 (phase IV/V EB, A: 44, A: 30 and A: 26 respectively), all older than dates of other graves from this phase, dates from graves E83, 8428, 8375, B85 and 5011 (phase IV EB, A: 38, A: 29, A: 29, A: 17 and A: 37 respectively), as well as dates from graves E110 and E220 (phase III EB, A: 6, and phase II/III EB, A: 10).

The poor consistency of the ten dates with the model does not mean that all of these dates are unrepresentative. For example, the inconsistency of the dates of samples C195, C95, B144, E83, 8428, 8375, B85 and 5011 is due to the fact that the calibrated ${ }^{14} \mathrm{C}$ dates of the first three samples from this group (IV/V EB phase) are most likely older than the calibrated dates of the remaining five (phase IV EB), while relative dating, with the chronological assumption of model A, suggests the opposite sequence of the dates of these samples. As a result, removing one or the other subgroup of samples from the model would automatically eliminate the incompatibility of the dates of the second subgroup of samples with the model. A similar discrepancy applies to samples E110 (phase III EB) and E220 (phase II/III EB).

The above observations make it necessary to revise the assumption of the chronological model. In the revised model (Model B, Fig. 1B), it was assumed that graves with equipment exhibiting features of two consecutive periods can be contemporaneous with graves from one or the other period. This assumption is much more reasonable than that of model A, because there is no doubt that changes in the stylistic features of man-made objects (which, being the equipment of studied graves, are the basis for relative dating) were of a fluid nature and objects with design elements of two subsequent periods could be manufactured at the same time as objects with characteristics of one or the other period. Bayesian analysis of model B gives a very good agreement index (Amodel: 97), definitely confirming its validity, in opposition to the artificially rigid' model A.

\section{The chronological framework of the periodization of the late Bronze Age and the early Iron Age on site in Domasław}

Bayesian analysis, in addition to clarifying information on the dates of individual samples, allows us to determine the absolute dates of time sections corresponding to the subsequent phases of the model (in this case: periods of relative chronology). The results of dating periods identified in the relative dating of graves from Domasław (Gediga, in this volume) are presented in Table 2.

Determined by models the $68 \%$ confidence intervals of dates of individual periods, are also shown in Fig. 4. It should be noted that the accuracy of determining the chronological frames is different for different periods. In particular, the two youngest periods (HD and LtA) are represented in Domasław only by individual samples, hence the timeframes of these periods outlined in Table 2 should be treated as approximate. On the other hand, to the HC period, the radiocarbon calibration curve has the Hallstatt plateau, meaning that the ${ }^{14} \mathrm{C}$ dates of materials formed between 750 and $400 \mathrm{BC}$ are almost all the same (see Fig. 6). For this reason, it is always difficult to precisely determine the calibrated dates of ${ }^{14} \mathrm{C}$ samples.

A comparison of the modelling results obtained here with the chronological frames of the J. Kostrzewski system published by J. Dąbrowski (2009) and reproduced in a later publication by B. Gediga (2013) indicates (Fig. 4) that the compliance of the Domasław model with the Dąbrowski scheme (2009) concerns only the youngest border HD - LtA. All earlier periods, in the Domasław models, look 100-200 years aged with respect to the Dąbrowski scheme, with the aging being the higher the older the periods. It is interesting that in the analyzed part of the past, the difference between the calendar age (cal BP) and radiocarbon age $\left({ }^{14} \mathrm{C} \mathrm{BP}\right)$ changes in a similar way. This difference (Fig. 5), exceeding 200 years around $1500 \mathrm{BC}$, decreases to about 100 years around $1000 \mathrm{BC}$ and about $500 \mathrm{BC}$ to around zero. This raises the question whether Dąbrowski (2009) in his construction of the chronological scheme did not calculate the radiocarbon years of $\mathrm{BP}$ for the $\mathrm{BC}$ calendar years by simply subtracting 1950 (the BP is counted to $1950 \mathrm{AD}$ ), ignoring the shape of the calibration curve. Unfortunately, Dąbrowski's publication is of a popular nature and the chronological scheme presented there is difficult to analyze based on the current state of knowledge in a strict manner.

If the chronological scheme published by Dąbrowski (2009) essentially presents radiocarbon dates reduced by 1950, its improvement would amount to the calibration of these dates. Such a 'corrected' scheme (Fig. 4) would be 
well suited to the chronological framework of the graves from Domasław, generally strengthening the credibility of the latter.

\section{Comparison of ${ }^{14} \mathrm{C}$ dating results of the cremation graves from Domasław and Kietrz}

A substantial series of radiocarbon dates from the same period as Domasław was previously obtained in the study of cremation graves from the burial ground in nearby Kietrz (Chochorowski 2007). In these studies, the radiocarbon dating of bones with the use of collagen (burned out due to cremation) was also not possible, and for the radiocarbon analysis the 'bone coal' or 'mass coal' (carbonate) fraction was used. Radiocarbon dates were obtained using the radiometric technique at the ${ }^{14} \mathrm{C}$ Laboratory in Kiev. The description of bone pretreatment used in these studies (Chochorowski 2007) is rather vague; one can guess that the 'bone coal' fraction is organic carbon, remaining after carbonate removal due to treatment with $\mathrm{HCl}$ solution and removal of humic acids in a $\mathrm{NaOH}$ solution, while 'mass coal' is the sum of organic carbon residues and carbon associated with the carbonate fraction. Additionally, several samples of charcoal were dated in the study of graves in Kietrz.

As noted by Chochorowski (2007), the ${ }^{14} \mathrm{C}$ dates of 'mass coal' may be rejuvenated, mainly with calcium carbonate precipitated from carbonate ions carried by groundwater. This effect, noticed by Chochorowski (2007), is illustrated in Figure 6, in which calibrated dates from Kietrz (with laboratory numbers Ki-) obtained by using the "massive coal' fraction are systematically younger than those from 'bone carbon' or charcoal samples hailing from the same periods.

As shown by the research of Lanting et al. (2001), misinterpretation of the radiocarbon dates of bones subjected to cremation at high temperature can be avoided by removing the remains of the organic fraction and decomposing the secondary carbonate grains as well as taking for ${ }^{14} \mathrm{C}$ measurement only the carbon released from the remaining apatite fraction. This pretreatment was used to date bones from Domasław in this work (see chapter: 'Methodology and results of radiocarbon dating ...'). The ${ }^{14} \mathrm{C}$ calibrated dates of bones from Domasław obtained this way are clearly older than the ${ }^{14} \mathrm{C}$ dates of 'mass coal' bones from Kietrz that come from the same periods (Fig. 6) and are certainly more correct. Of course, the amount of carbon obtained from the apatite fraction is very small, giving a chance for ${ }^{14} \mathrm{C}$ measurement only by using the AMS technique, inaccessible to the Kiev laboratory.
In the set of ${ }^{14} \mathrm{C}$ dates from Kietrz, closer to the Domasław dates (from the same periods), are those obtained for the 'bone carbon' fraction (Fig. 6). In particular, the date from grave 1147 in Kietrz (Ki-12671) from the $\mathrm{V}$ EB period falls in the middle of the phase ' $\mathrm{V}$ EB' dated by samples from Domasław, while the dates of graves 1713, 1152 and 544 in Kietrz (Ki-7050, Ki-12762, Ki-13080, $\mathrm{Ki}-13138$ and $\mathrm{Ki}-13081$ ), although on average younger than the Domasław dates of the 'IV EB' phase, do not go significantly beyond the time period set for this phase in Domasław. Nevertheless, it should be noted that it is not known whether the 'bone charcoal' of Kietrz's bones was associated exclusively with collagen (a bone fraction best suited for dating), or if it contained other groups of compounds. In addition, even when dating by the 'bone charcoal' of the bones from Kietrz, extraction of collagen was used, almost certainly no ultrafiltration was used (practically possible to perform only for milligram portions, suitable for ${ }^{14} \mathrm{C}$ measurement only by AMS technique). The omission of ultrafiltration (Bronk Ramsey et al. 2004; Brock et al. 2010) poses a danger of falsifying the ${ }^{14} \mathrm{C}$ date by the presence of atoms of 'younger' carbon attached to the ends of short amino acid chains resulting from the degradation of the original collagen molecules. It seems that, on average, the younger age of the samples of 'bone coal' dates from Kietrz in relation to the dates of the 'IV EB' phase from Domasław, may be the result of the failure to use collagen ultrafiltration.

In a publication on dating graves from the burial ground in Kietrz, Chochorowski (2007) concluded that 'in the early Lusatian population, using the burial ground in Kietrz, different cultural traditions could have been cultivated in parallel'. In the light of the discussion on the correctness of radiocarbon dates of samples from that site (and also taking into account the large laboratory uncertainties of the Kiev date marks), the above conclusion could be deemed poorly documented. However, this conclusion is strongly supported in dating graves from Domasław, in which of the two chronological models (A and B, Fig. 1) only the one assuming parallel formation of graves with equipment with characteristics of a given period and characteristic features of two periods proved to be acceptable.

\section{Reservoir effect}

When determining the chronological frames based on the ${ }^{14} \mathrm{C}$ dating of human bones, one must bear in mind the possibility of results' falsification due to the reservoir effect. Reservoir effect, occurring if a significant portion of the diet of dated individuals had water-based food (fish, 
crustaceans), can cause aging of the ${ }^{14} \mathrm{C}$ date even by hundreds of years (e.g. Olsen et al. 2010; Shishlina et al. 2014). Finding the contribution of such food to the diet of the dated individual requires analysis of the composition of stable carbon isotopes $\left(\delta^{13} \mathrm{C}\right)$, and above all nitrogen $\left(\delta^{15} \mathrm{~N}\right)$ in the collagen extracted from the bones (e.g. Pospieszny and
Bełka 2015; Goslar et al. 2017). Unfortunately, the lack of collagen in the examined bones precludes the possibility of such analysis, both in Domasław and in Kietrz. Thus, in this aspect of the analysis of the chronology of cremation graves from Domasław, we are doomed to uncertainty.

Otrzymano (Received): 23.10.2018; Zrecenzowano (Revised): 29.06.2019; Zaakceptowano (Accepted): 8.07.2019

\section{Adres Autora:}

Prof. dr hab. Tomasz Goslar

Uniwersytet im. Adama Mickiewicza

Wydział Fizyki

ul. Umultowska 85, 61-614 Poznań

Poznańskie Laboratorium Radiowęglowe

Poznański Park Naukowo-Technologiczny

ul. Rubież 46, 61-612 Poznań

e-mail: tomasz.goslar@radiocarbon.pl

(iD https://orcid.org/0000-0002-1346-3122 